\title{
LA ÚLTIMA SOR JUANA
}

\author{
POR \\ JEAN-MicheL WisSMER \\ Universidad de Ginebra
}

En 1693 Sor Juana Inés de la Cruz llamó otra vez a su antiguo confesor, el Padre Antonio Núñez de Miranda de quien se había despedido en 1682. Hizo una confesión general "para declararse la guerra y conquistarse del todo a sí misma" (Maza 150), como lo dice de forma tan poética $-\mathrm{y}$ tan sorjuanina - su biógrafo, el Padre Diego Calleja. Luego escribió un texto de penitencia que lleva el título de "Petición, que en forma causídica presenta al Tribunal Divino la Madre Juana Inés de la Cruz, por impetrar perdón de sus culpas". En este texto se declara "la más indigna e ingrata criatura", y dice: "ha tantos años que yo vivo en religión, no sólo sin Religión sino peor que pudiera un pagano"1 (OC IV, 520-521).

El 17 de febrero de 1694, firmó lo que Octavio Paz considera como "otro triste documento" (Paz 594), defendiendo la Purísima Concepción de María; y el 5 de marzo rubricó con su sangre una "Protesta" que, como aclara su epígrafe, "hizo de su fe y amor a Dios [...] al tiempo de abandonar los estudios humanos para proseguir, desembarazada de este afecto, en el camino de la perfección" (OC IV, 518).

Parece que no puede ser más clara su renuncia total a las letras profanas. Por eso, es sumamente importante analizar esta última producción y, sobre todo, acercarse al texto considerado como el último poema de Sor Juana a fin de buscar los elementos anunciadores de tal cambio. Este artículo no pretende dar respuestas definitivas (difícil ejercicio en el caso de Sor Juana) sino dar una visión crítica y contrastada entre las posibles interpretaciones de este misterioso texto.

Primero, veamos lo que la crítica opina a propósito de los textos piadosos que hemos mencionado al comienzo para averiguar si todavía sigue viva la Décima Musa. Los más eminentes sorjuanistas no obtienen la misma respuesta.

Para Paz,

el estilo impersonal de estos escritos, como copiados de un formulario devoto, revela o que Sor Juana no los escribió o que, renunciando efectivamente a la literatura, se atuvo a las fórmulas usadas ( $\mathrm{Paz} 595$ ).

\footnotetext{
${ }^{1}$ Todas las referencias a la obra de Sor Juana provienen de la edición de Alfonso Méndez Plancarte y Alberto Salceda, Obras completas de Sor Juana Inés de la Cruz (I-IV). Abreviamos OC.
} 
Hablando de la "Petición al Tribunal Divino" escribe Ezequiel Chávez : "[...] se diría, al leerla, que quien la firma, hubiese perdido, antes de escribirla, el juicio" (Chávez 226). En cambio, Marie-Cécile Bénassy no cree en una "Sor Juana mutilée" (Bénassy 179). Le impresiona que incluso ante el Tribunal de Dios hable de "voluntad y libertad". Utilizar la palabra "libertad" en el momento del sacrificio final extraña: "comment imaginer qu'elle l'ait employé si elle avait le sentiment intime que son changement de vie était une démission, une fuite ou une lâcheté?" (Bénassy 180).

Más sorprendente aún, tanto Bénassy como Paz lo han subrayado, es que, a pesar del título de esta "Petición", "ni dans ce texte, ni ailleurs, Sor Juana ne renie ses écrits profanes ou sacrés" (Bénassy 179). Sólo el epígrafe de la "Protesta" menciona claramente el hecho de "abandonar los estudios humanos", pero sabemos muy bien que los epígrafes no fueron compuestos por ella. ${ }^{2}$

Analizando la forma, Antonio Alatorre opina que en esta "Petición", "la coquetería literaria de la monja [...] sigue viva" y que "así como Sor Juana superó a Vieira en la Crisis, así en la Petición intentó superar a Núñez" (Alatorre 601). Y es verdad que el Padre Calleja hablaba ya de "una súplica en que no se estorban lo discreto y lo muy fervoroso" (la Maza 150). En cuanto a Salceda, le sorprende el vocabulario jurídico utilizado por la monja en este texto: "hasta en momento solemne y tratando de asunto tan personal y trascendental, no desdeña recurrir a formas curialescas" (OC IV, 671). Así que sólo la "Petición" conservaría ese "toque" personal de la poeta, lo que permite hablar con Salceda de "la última obra literaria de Sor Juana" (OC IV, 671).

Que se haya o no callado la voz de la monja escritora, lo que sí es cierto es que aceptó entregar al arzobispo de México, Aguiar y Seijas, su magnífica biblioteca, lo que fue quizá su mayor sacrificio como lo comenta Calleja:

La amargura, que más sin estremecer el semblante pasó la madre Juana, fué deshacerse de sus amados libros, como el que en amaneciendo el día claro apaga la luz artificial por inútil. Dejó algunos para el uso de sus hermanas, y remitió copiosa cantitad al $\mathrm{Sr}$. Arzobispo de México para que, vendidos, hiciese limosna a los pobres, y aún más que estudiados, aprovechasen a su entendimiento en este uso. Esta buena fortuna corrieron también los instrumentos músicos y matemáticos, que los tenía muchos, preciosos y exquisitos. Las preseas y bujerías y demás bienes ... todo lo redujo a dinero ... no dejó en su celda más que sólos tres libritos de devoción ${ }^{3}$ y muchos silicios y disciplinas (Maza 150-151).

Generalmente los críticos no comentan esta información importante: Sor Juana "dejó algunos [libros] para el uso de sus hermanas". ${ }^{4}$ No sabemos de qué libros se trata ${ }^{5}$ pero debieron tener bastante valía para que Sor Juana quisiese salvarlos de las manos "caritativas"

\footnotetext{
${ }^{2}$ Véase el artículo de Frederick Luciani, "Sor Juana Inés de la Cruz: epígrafe, epíteto, epígono" en la Revista Iberoamericana, 132-133, (julio-diciembre 1985), 777-783.

${ }^{3}$ El Padre Oviedo, biógrafo del Padre Núñez, habla de "unos pocos libritos espirituales que le ayudasen en sus santos intentos" (La Maza 281).

${ }^{4}$ Lo subrayado es nuestro.

${ }^{5}$ Oviedo no menciona estos libros.
} 
del arzobispo. El inventario preciso que hace Calleja permite confirmar también otro punto interesante, y es que el voto de pobreza no era respetado.

Sin embargo, a la muerte de Sor Juana, no había "sólo tres libritos de devoción"; se encontró también en su celda un poema "en borrador y sin mano última" (OC I, 448), como lo anotó Castorena y Ursúa, compilador y editor de Fama y obras póstumas de Sor Juana, libro que contiene precisamente este poema. Se trata de un romance "En reconocimiento a las inimitables Plumas de la Europa, que hicieron mayores sus Obras con sus elogios ..." (OC I, 158). Para Bénassy, este poema "est peut-être le dernier de tous" (Bénassy 177). Lo confirma Josefina Muriel:

Esta fué la última vez que Sor Juana tomó la pluma, y con sentimiento de las letras castellanas, porque si en este tiempo hubiese escrito, séame permitida la suposición, tendríamos su mejor aportación a la mística mexicana (Muriel 295).

Si fue realmente "la última vez que Sor Juana tomó la pluma", nos parece muy curioso que la crítica no se haya extrañado más ante algo tan sorprendente. Parece efectivamente asombroso que se haya encontrado en la celda de la monja un poema que da las gracias a todos los admiradores de su genio literario, un poema cuyo tema central es su admirable fama, o sea, precisamente todo lo que había sacrificado o que "hubiera debido" sacrificar.

Fechar la producción de Sor Juana ha sido siempre un grave problema, y más aún cuando se trata de lo que la crítica considera como el "último" poema. Paz piensa que lo escribió a fines de 1692 y añade: "Por lo visto, su renuncia a las letras no fue tan definitiva como para destruir ese último poema" (Paz 591-592). En cuanto a Chávez habla de una composición del poema "en los últimos días de su vida" (Chávez 234). Si lo escribió tan tarde tendríamos que imaginar que, siendo ya la monja penitente, compuso todavía un poema lleno de gracia cortesana. Nada sería sorprendente en este gran teatro de engaños y trampas que era el mundo barroco, mundo al que pertenecía por completo Sor Juana. Sin embargo, aunque puede parecer curioso (y veremos que tal vez no lo sea tanto) que haya escrito este poema en plena reconversión y penitencia, queda la realidad histórica de los hechos: no destruyó este texto ni lo entregó al arzobispo con los libros. Tendremos que preguntarnos el porqué.

Hay otra cuestión importante ya que el poema está inacabado. Esto podría significar que dejó de componerlo en un momento decisivo de su reconversión, o, siguiendo a Chávez, al momento de morir.

Desafortunadamente, no tenemos las respuestas a estas preguntas, pero podemos, por lo menos, tratar de comprender mejor el misterio acercándonos al texto.

En realidad hay dos formas de analizar el poema. La primera es considerarlo como un ejemplo perfecto del tópico de humildad; la segunda, como una forma de ejercicio de penitencia, lo que le quitaría esta impresión de "engaño barroco" que describíamos antes. mujer":

Veamos la primera. Sor Juana se maravilla ante tantos aplausos para "una ignorante 


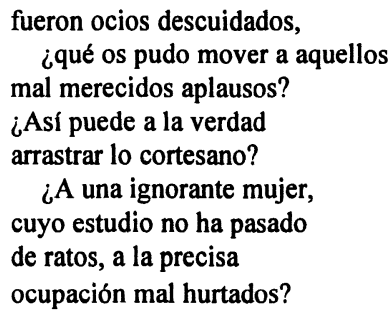

Su obra está llena de expresiones de falsa humildad como las que tenemos en este extracto ("ignorante mujer", "borrones") y que esconden en realidad el significado opuesto (la "ignorante mujer" es muy consciente de su cultura). Dice, por ejemplo en la Respuesta: “¿Por ventura soy más que una pobre monja, la más mínima criatura del mundo y la más indigna de ocupar vuestra atención?" e insiste (porque ya sabe que resultará difícil creerla): "No es afectada modestia" (OC IV, 441). Sin embargo, sabemos muy bien cómo la "ignorante mujer" llena su respuesta de las más doctas y rebuscadas referencias. Ese tópico de la época; ${ }^{6}$ ya muy frecuente para cualquier escritor, era casi obligatorio para una "sospechosa" mujer culta. Además, Sor Juana ya sabía por experiencia propia que recibir elogios no le facilitaba la vida; era más bien lo contrario. Las primeras publicaciones de Inundación castálida en España con los textos de los aprobantes elegidos por la condesa de Paredes, defendiendo el derecho de escribir para una monja, y atacando la santa ignorancia, exasperaron a los enemigos de Sor Juana en México que no soportaron estas lecciones dadas desde la Península. Conocemos el resultado: poco después de la publicación del segundo tomo de su obra (y de su llegada a México) se sitúa la confesión general de Sor Juana y su abandono de la letras. Así que una humildad, incluso fingida, podía a veces calmar las conciencias.

Para Paz, la que escribe este poema es la Sor Juana de siempre:

El romance no revela el más mínimo deseo de abandonar la literatura o de cambiar de estilo de vida; al contrario, continúa los temas de la Respuesta [...] Una persona que escribe con tanta efusión y entusiasmo de su oficio no está en vísperas de abandonarlo (Paz 592).

Chávez comparte este punto de vista:

[...] no obstante las externas apariencias - de una radical transformación de su ser[Sor Juana] había seguido y siguió siendo el alma misma [...] que siempre había sido, y que lo fue hasta el fin, aunque las estrofas que al fin compusiera [...] no alcanzarán, quizás, permiso para alejarse de ella, ni tuvieran ya fuerzas para salir de su celda, y volar a su destino (Chávez 234-235).

\footnotetext{
${ }^{6}$ Véase la nota 96 (página 649) de Antonio Alatorre en su artículo de la Nueva Revista de Filologia Hispánica antes mencionada.
} 
Como lo señala Chávez, el hecho de que el poema no esté acabado nos da quizá otra llave: no tuvo Sor Juana el tiempo —o la posibilidad— para defenderse más: su realidad era ya otra.

Es verdad que, a primera vista, este poema podría compararse con cualquier otro de su momento de gloria. Tenemos a la cortesana que se dirige a los "Ingenios más claros" como si fuera una tertulia literaria en el palacio ("¿Así puede a la verdad arrastrar lo cortesano?"); aquí está la mexicana orgullosa de las "mágicas infusiones de los Indios herbolarios de mi Patria"; tampoco falta la mujer culta —quizá un poco pedante—que no puede dejar de citar referencias culturales (Faetonte, Narciso, la fábula del pavo) y elementos científicos (como su explicación sobre la penetración del sol en "cuerpos opacos"); y también tenemos a la mujer irónica - y feminista avant l'heure - que nunca pierde una ocasión para hablar de la condición de su sexo.

Ahora bien, siendo el "último" poema, no puede ser "cualquier" poema, y teniendo en cuenta el contexto de su composición y de su descubrimiento, pensamos que hay lugar para un análisis muy diferente que vamos a proponer al juicio de los lectores.

En efecto, podemos considerarlo como el reflejo de un verdadero desprecio por parte de la monja que miraría su época de fama con la distancia de quien ya no pertenece a este mundo. Dice:

\footnotetext{
Vergüenza me ocasionáis

con haberme celebrado, porque sacan vuestras luces mis faltas más a lo claro.
}

Se considera como un "rústico aborto de unos estériles campos" utilizando la metáfora del parto/aborto que encontramos en varios poemas." Los campos son "estériles", "agostados", la educación "inculta", todo parece seco y muerto como en los bodegones de Juan Sánchez Cotán, este pintor lego español (1560-1627) fascinado por los cardos. En este caso la palabra "naturaleza muerta" conviene a maravilla. Además, gran parte del poema se baña en una atmósfera de luz y sombra, conectando perfectamente con el espíritu tenebrista de la pintura de la época ("sacan vuestras luces mis faltas más a lo claro" o "sólo de ocasionar sombras les sirve lo iluminado").

En la decimoctava estrofa se compara con Faetonte y Narciso, y exclama: ¡cuántas veces ...
o hubiera muerto Faetonte
o Narciso peligrado,
a no tener en mí misma
remedio tan a la mano
como conocerme, siendo
lo que los pies para el pavo!

\footnotetext{
7 Véase el romance "Finjamos que soy feliz" $(O C \mathrm{I}, 5)$ : “¿De qué sirve al ingenio / el producir muchos partos,/ si a la multitud se sigue / el malogro de abortarlos?"
} 
Tenemos aquí un ejemplo perfecto de la creación literaria sorjuanina. Ella utiliza todos los recursos de su época, tanto en el estilo como en los temas. Las figuras de Faetonte -con su doble Ícaro-y de Narciso fueron muy difundidas como arquetipos de la temeridad y de la vanidad. Ahora bien, ya no son alegorías desencarnadas; aquí, son puras proyecciones de la poeta quien, personalizando totalmente las figuras mitológicas, hace de ellas ejemplos característicos de su propio ser y de su propia experiencia. " ¡Cuántas veces hubiera muerto!", nos dice, "encandilada en tanto golfo de rayos" (hilando la metáfora luz / sombra). Morir muchas veces, y no sólo por los "no merecidos loores" que la precipitaban en el peligro de la autosatisfacción, sino también, como lo recuerda en la Respuesta, "porque entre las flores de esas mismas aclamaciones se han levantado y despertado tales áspides de emulaciones y persecuciones, cuantas no podré contar" (OC IV, 452).

Luego, hace alusión al pavo de la fábula de Fedro que, a pesar del esplendor de su cola, está avergonzado de ver sus "pies" tan feos. Esta aparición de lo feo en medio de la belleza es un recurso típico del Barroco, el duro recuerdo de nuestra condición humana, débil y mortal, la calavera en medio de todos los símbolos de la vida y de los placeres en esas vanitates del siglo XVII. El pavo es, en la tradición cristiana, símbolo de inmortalidad; así que no se trata solamente de un contraste entre la belleza y la fealdad sino también entre la vida y la muerte.

Ya lo hemos visto, el poema está precisamente lleno de metáforas de la muerte, pero aquí está la más fuerte:

\footnotetext{
Honoríficos sepulcros de cadáveres helados, a mis conceptos sin alma son vuestros encomios altos: elegantes Panteones, en quienes el jaspe y mármol Regia superflua custodia son de polvo inanimado.
}

Sor Juana nos había hablado ya de la muerte y de la vanidad pero raras veces con esta amargura. Su visión de "sepulcros" y "cadáveres helados" recuerda la terrible pintura de Valdés Leal, "Finis Gloriae Mundi", en el Hospital de la Santa Caridad en Sevilla, y confirma que el poema pertenece al género de la vanitas.

Es de notar cómo Sor Juana se aplica a ella misma los atributos normalmente reservados a los hombres (el estudio, los libros, la creación literaria) rechazando (como en su famoso soneto "En perseguirme, Mundo, ¿qué interesas? ...") todo lo que se atribuye tradicionalmente a la mujer vanidosa (la belleza con sus símbolos: el espejo, las alhajas, etc.).

Castorena había anotado:

Este Romance, que aun entre la valentía de los números muestra en la Poetisa lo humilde de su genial desconfianza, se halló así, después de su muerte, en borrador y sin mano última. No ha parecido convenir que, de muchos Ingenios que lo deseaban, alguno lo fenezca: o porque no hay luz artificial, por mucho que brille, bastante a ser remedo del 
Sol, aun ya moribundo; o porque se imprima mejor en nuestra lástima el concento último y finísimo del Cisne que expiró (OC I, 448).

El comentario de Castorena es interesante porque, primero, demuestra que no le parece nada fingida la humildad de Sor Juana, y que incluso añade a su talento, como lo dice de forma todavía tan barroca ("lo humilde de su genial desconfianza"). Vemos que utiliza también abundantemente la metáfora luz/sombra. En cuanto al cisne, es un animal simbólicamente muy rico. Tanto en la nota de Castorena como en el poema de Sor Juana (“dulcísimos Cisnes"), el cisne representa al poeta inspirado (en la mitología griega acompaña a Apolo, dios de la música y de la poesía). Castorena lo describe expirando, imagen bastante difundida en la poesía cuando se trata del amante muriéndose de amor. Este canto del Cisne se encuentra, por ejemplo, en la endecha "Si acaso, Fabio mío" en la cual escribe Sor Juana:

\author{
oye, en tristes endechas, \\ las tiernas consonancias \\ que al moribundo cisne \\ sirve de exequias blandas (OC I, 201).
}

El cisne simboliza dos tipos de luces: una luz solar, masculina, y una luz lunar y femenina, lo que afirma su carácter andrógino. Hemos visto la importancia de la luz en el poema. En cuanto al tema andrógino en Sor Juana, ya hizo correr mucha tinta. En el poema la poeta no se masculiniza puesto que se define como una "ignorante mujer". Sin embargo, insiste irónicamente sobre el hecho de que lo exagerado del elogio viene precisamente de su sexo:

\footnotetext{
Si no es que el sexo ha podido

o ha querido hacer, por raro,

que el lugar de lo perfecto

obtenga lo extraordinario.
}

Tanto el cisne como el pavo están ligados por el simbolismo de la muerte. Podríamos añadir el fénix, otro símbolo de creación artística y de inmortalidad que se aplicó a Sor Juana como "Fénix de México".

Considerar este último poema como el poema del desengaño, de una despedida de la gloria y del mundo, permite evidentemente ligarlo perfectamente con la reconversión de Sor Juana y su sacrificio final. Es lo que sugiere Méndez Plancarte cuando dice en su nota sobre los "pies" feos del pavo: "Pero Sor Juana nunca más alta y buena que cuando se juzgaba la peor ..." (OC I, 448), haciendo una alusión clara al testamento de la monja donde se define como "la peor del mundo" (OC IV, 523).

Sin embargo, no hace falta esperar su testamento para encontrar esta forma de autodesprecio cuyos ejemplos son innumerables en toda su obra.

Los problemas de su persecución y de su sacrificio final son todavía de los más debatidos. Todo el mundo admira a la Sor Juana combatiente, a la feminista avant l'heure, y queda impresionado por sus convicciones y su fuerza de carácter. Sin embargo, existe 
desde el comienzo una Sor Juana dolorosa y dolorida que llena su obra de quejas y de autodesprecio que van mucho más allá del tópico de humildad que mencionamos antes. Sabe perfectamente que la sociedad de su tiempo no tolera a mujeres que no cumplen con los deberes tradicionales, es decir, los de buena esposa o buena religiosa. Interiorizó todo este mensaje negativo.

La "última Sor Juana", la de los textos piadosos, la que se despide del mundo en su último poema, sabía - tal vez desde la infancia - que iba a ser una "mártir de la inteligencia" (Castro 161) para utilizar las palabras de Américo Castro. Así que no creemos realmente en una ruptura completa entre una Sor Juana cortesana, poeta del amor profano, racional, intelectual y narcisista, y una Sor Juana católica, penitente y autodespreciativa. Por eso, el último poema nos parece tan importante, porque a pesar de sus contradicciones y de la dificultad de su interpretación $\multimap$ tal vez gracias a ellas - nos puede servir de puente entre las dos Sor Juana.

El misterio de las dos caras de Sor Juana tiene una de sus explicaciones en la Respuesta donde expresa lo que es la interrogación clave de su destino: "trájeme a mí conmigo y traje mi mayor enemigo en esta inclinación, que no sé determinar si por prenda o castigo me dio el Cielo" (OC IV, 447). Esta duda está en el centro de la lucha que Sor Juana armó a veces contra ella misma, otras veces contra sus enemigos. Son famosas las declaraciones de Sor Juana sobre su "repugnancia" a hacer versos, y el carácter forzado de su creación literaria: "[...] yo nunca he escrito sino violentada y forzada y sólo por dar gusto a otros; no sólo sin complacencia, sino con positiva repugnancia [...]" (OC IV, 444). Es evidente que hay que "traducir" estas palabras y ponerlas en su contexto: primero, la Respuesta es un texto de defensa y de justificación dirigido a un eminente hombre de la Iglesia; segundo, es verdad que casi toda la obra de Sor Juana es obra de encargo (con la excepción del Sueño, nos dice ella). Sin embargo, esta explicación no nos satisfece totalmente. Ya en la Carta de Monterrey, o sea nueve años antes, decía: "estos [los versos] los aborresco de forma que no avrá para mí penitencia como tenerme siempre haciéndolos" (Alatorre 625).

Las trampas del mundo barroco nunca han sido tan engañosas como en el caso de Sor Juana. "Penitencia" y "repugnancia": estas palabras pueden ser máscaras de una hábil cortesana, y, así como la falsa humildad, esconder el mensaje opuesto. Nunca hay que perder de vista este aspecto del personaje y de su contexto cultural. Sin embargo, estamos convencidos de que esta "repugnancia" pudo corresponder a una cierta realidad, perfectamente reflejada en su obra, y que, en este caso, no se trata de un puro juego literario y retórico. Hay varios ejemplos que prueban que Sor Juana consideraba su genio literario y su afán de investigación como una fatalidad, una necesidad obsesiva y fatigosa, y, como lo hemos visto, un castigo de Dios. Explica en la Respuesta cómo, incluso durmiendo, seguía "arguyendo, haciendo versos" (OC IV, 460), y dice en un romance:

Sírvame el entendimiento

alguna vez de descanso,

y no siempre esté el ingenio

con el provecho encontrado $(O C \mathrm{I}, 5)$.

Es fácil entender cómo entre su sed inagotable y obsesiva de saber y escribir, y la persecución que sufrió por ella, debió a veces odiar todo lo que era. Es evidente que era un 
"caso": no era "normal" en esta época que una mujer supiera tanto. Conocemos el episodio de la prueba en el palacio cuando Juana dejó con la boca abierta a toda la "crema intelectual" del México de entonces. Es consciente de ser un fenómeno, un "monstruo" como lo escribe en un romance ( $O C \mathrm{I}, 147)$.

Sin duda tuvo un conflicto interior bastante doloroso entre lo que era y el modelo que le ofrecía la sociedad de su tiempo. Así se puede entender cómo quiso a veces rechazar todo lo que encarnaba. Si la contradicción es un recurso del Barroco, Sor Juana se sirve también de este recurso para expresar una realidad psicológica profunda. Cuando dice en la Respuesta que pidió a Dios "que apague la luz de mi entendimiento dejando sólo lo que baste para guardar su Ley" y que "no consiguiendo esto, he intentado sepultar con mi nombre mi entendimiento" (OC IV, 444-445), hay que creerle, incluso si no corresponde en absoluto a otras declaraciones suyas.

La vida y la obra de Sor Juana se inscriben dentro de un triángulo opresor formado por la fatalidad divina ("prenda" o "castigo" de Dios), los enemigos reales, y ella misma. Este último aspecto es muy importante. En efecto, al lado del determinismo y de la persecución, Sor Juana defiende su libertad, ilustrando de forma magistral el libre albedrío del hombre, tan importante en el catolicismo de la Contrarreforma y correspondiendo a sus propias convicciones. Se siente responsable de sí misma tanto para lo mejor como para lo peor. Dice en la Carta de Monterrey: "Yo tengo este genio. Si es malo, yo me hize. Nací con él y con él he de morir" (Alatorre 263). De ahí también todas las alusiones a su auto-tortura como en la Respuesta: "Rara especie de martirio donde yo era el mártir y me era el verdugo" (OC IV , 452). Su obra está llena de quejas dirigidas tanto al "Mundo" ("En perseguirme, Mundo, / ¿qué interesas?” (OC I, 277)) como a ella ("De mí mesma soy verdugo / y soy cárcel de mí mesma" (OC I, 168)).

Se suele siempre dividir la vida de Sor Juana en dos partes: su gloria literaria y su renuncia a las letras, como si fueran dos mujeres distintas. Pensamos que hay que matizar bastante esta visión tradicional. Ahora, o bien la monja penitente siguió siendo la mujer fuerte y no abandonó su pasión literaria ni sus convicciones (como lo sostienen algunos críticos que mencionamos al comienzo de este artículo), o bien la Sor Juana de la primera época ya tenía profundamente interiorizadas las nociones de sacrificio y autodesprecio.

A pesar de la imagen tan difundida de Sor Juana como la "antimonja perfecta", su vida y su obra se inscriben dentro de su destino religioso y no fuera. Luchó por la inteligencia y el derecho al saber dentro de la Iglesia. Su sacrificio final representa quizá la conclusión lógica de la vida de una mujer convencida de ser un "nuevo género" de mártir. Muchas veces se compara con mujeres famosas de la historia, tanto santas y mártires cristianas como sabias o poetas de la Antigüedad, para indicar que pertenece a esta larga lista de mujeres que defendieron la inteligencia de forma tan activa. El mejor ejemplo es sin duda el de Santa Catarina. En los famosos villancicos que le dedicó (OC II, número 312-322), nos presentaba a la "egipcíaca" como el modelo de la santa docta: "Tutelar sacra Patrona, / es de las Letras Asilo". Y se exclamaba: “¡Víctor, víctor!” Que se haya proyectado en la figura de esta santa parece evidente: su victoria era un poco la suya. Ella también había demostrado que "... el sexo / no es esencia en lo entendido" y había asombrado a "todos los Sabios"; ella también "porque es bella la invidian, / porque es docta la emulan ..." Es impresionante como parece que quiso imitarla hasta en el sacrificio: Sor Juana rubricó con 
su sangre su "Protesta de fe" que significaba el sacrificio de su vida literaria, y, cantando el martirio de la santa, escribe:

\author{
Perdióse (¡oh dolor!) la forma \\ de sus doctos silogismos: \\ pero, los que no con tinta, \\ dejó con su sangre escritos.
}

Este villancico es uno de los últimos textos de Sor Juana (1691) y la referencia a su "Protesta de fe" no es nada casual. Ya no era tiempo para la estética de la tinta, había llegado el verdadero sacrificio de sangre y la penitencia dolorosa. En este contexto, el último poema resuena de forma muy aguda. Nos preguntamos si "Los Sabios de Egipcio" no podrían ser esos "Númenes divinos", esos "Ingenios" del último poema inacabado.

Tal vez conservó su último poema porque era la ilustración perfecta del contraste entre su gloria literaria y el "polvo inanimado" de una muerte tan presente en esta Nueva España de los años 1691 y 1692, hundida en las calamidades climáticas y las agitaciones sociales. Por eso, podemos considerar este "último poema" como esos bodegones, esas vanitates, puestos en los monasterios para recordar a los religiosos que sólo por el rechazo de los bienes de este mundo y la glorificación de Dios se llegaba a la salvación del alma.

De todas formas, que se trate del "único" poema salvado por la monja o del "último" escrito por ella, vemos que toda literatura no estaba muerta en la celda de la penitente. Sin embargo, como lo sabemos, se calló de repente la voz de la Décima Musa de México. El silencio final de Sor Juana impresiona. Es como la noche de su Sueño: "todo, en fin, el silencio lo ocupaba" (OC I, 339), este silencio contra el que siempre se había rebelado, un silencio impuesto desde hacía demasiado tiempo, y que llevó a Sor Juana a reinterpretar el famoso "Mulieres in Ecclesiis taceant".

Este silencio es también aquél de este último poema que acabamos de analizar, el silencio enigmático de sus puntos suspensivos ...

\title{
Obras citadas
}

Alatorre, Antonio. "La Carta de Sor Juana al P. Núñez (1682)". Nueva Revista de Filología Hispánica, XXXV/2. México: El Colegio de México, 1987.

Bénassy-Berling, Marie-Cécile. Humanisme et Religion chez Sor Juana Inés de la Cruz. La femme et la culture au XVIIe siècle. Paris: Editions hispaniques, Publications de la Sorbonne, 1982.

Chávez, Ezequiel A. Sor Juana Inés de la Cruz. Ensayo de psicología y de estimación del sentido de su obra y de su vida para la historia de la cultura y de la formación de México. 1931. México: Porrúa, 1981.

Castro, Américo. De la edad conflictiva. Crisis de la cultura española en el siglo XVII. Madrid: Taurus, 1976.

Maza, Francisco de la. Sor Juana Inés de la Cruz ante la historia. México: Universidad Nacional Autónoma de México, revisión de Elías Trabulse, 1980.

Méndez Plancarte, Alfonso y Alberto G. Salceda. Obras completas de Sor Juana Inés de la Cruz. México: Fondo de Cultura Económica, 1988. 
Obras completas de Sor Juana Inés de la Cruz I (Lírica personal). 1951.

Obras completas de Sor Juana Inés de la Cruz II (Villancicos y Letras sacras). 1952.

Obras completas de Sor Juana Inés de la Cruz III (Autos y Loas). 1955. Obras completas de Sor Juana Inés de la Cruz IV (Comedias, Sainetes y Prosa). A. Salceda, editor. 1957.

Muriel, Josefina. Conventos de monjas en la Nueva España. México: Editorial Santiago, 1946.

Paz, Octavio. Sor Juana Inés de la Cruz o las trampas de la fe. 1982. Barcelona: Editorial Seix Barral, 1989. 
